\title{
ANIMAL EXPERIMENTATION
}

\author{
Fimbrial Capture of the Ovum and Tubal Transport of the \\ Ovum in the Rabbit, with Emphasis on the Effects of \\ $\beta_{2}$-Adrenoreceptor Stimulant and Prostaglandin $F_{2} \alpha$ on \\ the Intraluminal Pressures of the Tubal Ampullae
}

\author{
HISAO OSADA, $, 1,3$ TOM KIYOSHI FUJII, ${ }^{1}$ IKUO TSUNODA, ${ }^{1}$ KENJIROH TAKAGI, ${ }^{\prime}$ KAZUO SATOH, ${ }^{1}$ \\ KIICHI KANAYAMA, ${ }^{1}$ and TSUYOSHI ENDO ${ }^{2}$
}

Submitted: November 18,1998

Accepted: February 22, 1999

Purpose: Our purpose was to elucidate the roles of the ampullar and isthmic portions of the oviduct and the effects of drugs on oviductal contractility.

Methods: Prostaglandin $F_{2} \alpha\left(P G F_{2} \alpha ;\right.$ Ono Pharmaceuticals, Osaka) and oxytocin (Atonin-O; Teikoku Hormone Manufacturing Co. Ltd., Tokyo) were used to stimulate oviductal contractility, and ritodrine hydrochloride (Utemerin; Solvay-Duphar Corp., Denmark) to inhibit the contractility. Results: Both $P G F_{2} \alpha$ and Atonin- $O$ were involved in ovum capture by the ampullar oviduct by stimulating contractility, thus altering the intraductal pressures. Utemerin is effective in inhibiting the enhanced contractility induced by $P G F_{2} \alpha$ and Atonin- $O$.

Conclusions: Variations in pressure of the ampullar portion of the oviduct seem necessary for the capture of ova expelled from the ovary. Once in the isthmic portion of the oviduct, transport appears to be under the influence of ciliary activity rather than variations in contractility.

KEY WORDS: ovum capture; ovum transport; intratubal pressure; $\beta_{2}$-adrenoreceptor stimulant; prostaglandin $F_{2} \alpha$.

${ }^{1}$ Department of Obstetrics and Gynecology, Nihon University School of Medicine, Nihon University Surugadai Hospital, 1-813, Kanda-Surugadai, Chiyoda-ku, Tokyo 101-0062, Japan.

2 Department of Veterinary Physiology, College of Bioresource Science, Nihon University, 1866 Kameino, Fujisawa 252-8510, Japan.

${ }^{3}$ To whom correspondence should be addressed.

\section{INTRODUCTION}

Progress in assisted reproductive technology has necessitated intensive study of fertilization and the development of the zygote. Thus, the role of the fallopian tubes and the specific functions of tubal physiology have become of great interest. The tubes are known to be important for the transport of sperm, nurturing of the ovum, fertilization, and the subsequent development and transport of the zygote prior to nidation.

The fimbria in rabbits at the time of ovulation approach the ovaries and envelop the expulsion site. During laparoscopic observations a similar phenomenon has been observed in humans. This phenomenon is considered to be of importance in the capture of the ovum. However, the definitive mechanisms involved in causing the increase in fimbrial motility, and its envelopment of the expulsion site and active capture of the ova and follicular fluids, have not as yet, been adequately clarified. The fimbria demonstrate an increase in activity near ovulation. It has been reported that during the follicular phase, the activity in the ampullary portion of the tube is enhanced. The mechanisms involved in the capture and transport of the ovum can easily be associated with the observed phenomena of enhanced smooth muscle activity in the ampullaris and fimbria, together with the smooth muscle contractions of the ampulla at ovulation $(1,2)$. 
This investigation involves the serial measurement of intrafallopian tubal pressures during the periovulatory period, using a calibrated pressure analog adapter inserted into the tubal lumen. This project was designed to investigate tubal activity in the periovulatory period, the effects of various drugs on either the stimulation or the inhibition of tubal activity, and their role in ovum capture and transport. Our test animals were domestic Japanese white rabbit females and the materials tested were $\beta_{2}$-adrenoreceptor stimulant, Utemerin, prostaglandin $\mathrm{F}_{2} \alpha\left(\mathrm{PGF}_{2} \alpha\right)$, and Atonin-O.

\section{MATERIALS AND METHODS}

The test animals were female white Japanese rabbits weighing $3.0-3.5 \mathrm{~kg}$. Automated signaling devices were installed under intravenous anesthesia to measure serial tubal activity and pressure. The rabbits were allowed a recovery period of 2-4 weeks to allow a return to physiologic responses. The telemetry system used (a) an implantable miniature transmitter which continuously senses, processes, and transmits information from within the animal (Data Sciences, Inc., USA); (b) a receiver located within or near the cage (Data Sciences, Inc.); (c) a recording system (NEC-Sanei TR41); and (d) a computer-based data acquisition system which collects, displays, and stores the telemetered data (Data Quest 3). The transmitters comprised of a sensor, an amplifier, a transmission circuit, and a battery, contained in a round 20-mm-diameter $\times 3$-mm-thick component, and were anchored subcutaneously. The life span of these transmitters was roughly 2 months. The pressure sensors consisted of a urethane catheter, $2 \mathrm{~mm}$ in diameter, which was anchored centrally in the lumen of the ampullary portion of the tube via an abdominal route and the sensor inserted into the fimbrial ostium and plugged with a biocompatible gel to prevent invasion by abdominal fluids. The catheters were filled with a noncompressible fluid. The pressure gradients sensed at the plugged ends were automatically transmitted to the telemetry monitor. To reduce trauma and minimize adhesion formation, all procedures were performed by microsurgical techniques using $10-0$ or $9-0$ nylon sutures. Transmitted signals were received and amplified with a bioelectric amplifier (NEC-Sanei 1253A) and recorded by a pen recorder and date recorder (NEC-Sanei 7R41). The signal recorded on the data recorder was analyzed by a computer system (NEC-Sanei signal processor
7R18), underwent analog-digital conversion, and was then submitted to a fast Fourier transform (FFT).

Ovulation was induced with 100-150 IU of human chorionic gonadotropin (hCG) injected into a vein of the ear. We attempted to determine whether the phenomenon of ovulation instigated or induced an increase in tubal contractility to synchronize with the expulsion of the ovum to enhance ovum capture. The rabbits were injected with 100-150 IU of hCG in a $1-\mathrm{ml}$ bolus intravenously (i.v.) into an ear vein to induce ovulation.

Following the hCG injection, we investigated the effects of Utemerin and $\mathrm{PGF}_{2} \alpha$ on ovum capture. We administered Utemerin in 1-mg doses intramuscularly (i.m.), starting 90 min prior to the estimated time of ovulation in hCG-primed rabbits (10 hourly injections). After the last injection of Utemerin, we laparotomized the rabbits $(N=5)$ and dissected out the fallopian tubes, taking care to remove the ampullae and isthmic portions separately. We then carefully lavaged the tubal portions with physiologic saline to determine whether any ova had been captured and transported. Another group was injected with Utemerin as above, then injected with $1 \mathrm{mg}$ of $\mathrm{PGF}_{2} \alpha$ four times $(30,90,150$, and $210 \mathrm{~min}$ postovulation), and examined as above $(N=5)$.

We then investigated the effects of Utemerin on the transport of ova in the tubes. This was performed in three groups of rabbits ( $N=5$ /group). The first group was injected with $1 \mathrm{mg}$ of Utemerin hourly (44 injections), starting $1 \mathrm{hr}$ postovulation. The second group had their first injection $6 \mathrm{hr}$ postovulation, and the third group received their first injection $12 \mathrm{hr}$ postovulation. All three groups received a total of 44 hourly injections to maintain uniformity of conditions. The tubes were carefully dissected to evaluate the degree of ovum transport. The ampullae were severed at the ampullar-isthmic junction (AIJ), then the isthmic portion was carefully trisected, the most distal portion being from the AIJ to the free isthmic portion. The midportion was free isthmic tissue, and the medial portion was free isthmic tube to the isthmic-uterine junction (IUJ). The uterine cavity and all four segments were carefully lavaged with physiologic saline and evaluated for the presence or absence of ova.

As controls, we evaluated the effects of Utemerin and Atonin-O on tubal contractility on rabbits which did not receive $h C G$. The rabbits $(n=5)$ received either Atonin-O or $\mathrm{PGF}_{2} \alpha$ as a simple bolus, and the changes in intratubal pressures were evaluated. 


\section{RESULTS}

In a control series $(N=5)$, we investigated the effects of Utemerin, Atonin-O, and $\mathrm{PGF}_{2} \alpha$ on intact tubes without hCG-induced ovulations. Both Atonin$\mathrm{O}(0.015 \mathrm{IU} / \mathrm{kg}$ i.v. $)$ and $\mathrm{PGF}_{2} \alpha(0.015 \mathrm{mg} / \mathrm{kg}$ i.v. $)$ caused a marked increase in tubal activity, as seen in the telemetered recording. Utemerin $(0.15 \mathrm{mg} / \mathrm{kg}$ i.v. $)$ administered during the stimulated condition caused a rapid inhibition to baseline pressures (Fig. 1).

To determine whether the increased tubal activity was in synchrony with ovulation, we continuously monitored tubal intraluminal pressures from after hCG administration until after ovulation had occurred. The intratubal pressures were $4.8 \pm 2.2 \mathrm{~mm} \mathrm{Hg}(N=5)$. This condition remained stable until $9.5 \pm 1.6 \mathrm{hr}$ $(N=5)$ post-injection of hCG, at which time a marked reduction in pressure was noted. Thus, a rapid drop in ampullar pressure appears to occur just after ovulation, suggesting a response in reaction to the ampullar tissues being exposed to follicular contents. It is believed that this drop in ampullar pressure results in drawing the ovum into the ampulla from the abdominal cavity. This was followed by a rapid recovery. Intratubal pressures then increased to $11 \pm 5.2 \mathrm{~mm} \mathrm{Hg}(N=5)$, and there was a disparity between contractions and relaxations. This enhanced activity continued for roughly $5 \mathrm{~min}$, after which intratubal pressures returned to control conditions. Subsequently, there was about 20 min of periodic light variations in tubal pressure, accompanied by increased tubal contractions.

The information telemetered from the rabbit tubal ampullae indicated a surge in tubal activity coincident with ovulation. Figure 2 shows the response elicited in one rabbit. Our data suggest, from the evidence of variations in intratubal pressures, that this rabbit ovulated three times. Responses were recorded serially following the intravenous injection of hCG. Figure 3 shows the power spectrum of the tubal intraluminal pressure gradients of the rabbit ampulla.

The effects of $\mathrm{PGF}_{2} \alpha$ and Utemerin on ovum capture were as follows: (a) Utemerin, 1 mig i.m., was administered hourly seven times, starting $90 \mathrm{~min}$ before ovulation $(N=5)$. We observed 8.6 ovulations. However, on examining the ampullae and isthmic portions of the tube, we were unable to detect the presence of ova, suggesting that Utemerin was succesful in inhibiting ovum capture by the ampullae. (b) In another group $(N=5)$ treated with Utemerin as above, we injected $\mathrm{PGF}_{2} \alpha, 0.015 \mathrm{mg} / \mathrm{kg}$ i.v. hourly, three times, starting 30 min postovulation. We detected an average of 7.4 ova per rabbit, from an estimated 8.2 ovulations, indicating that $\mathrm{PGF}_{2} \alpha$ overrode the effects of Utemerin and resulted in a $90.2 \%$ ovum capture.

The effects of Utemerin on ovum transport in the fallopian tubes were as follows: (a) In the group $(N=5)$ which received Utemerin, $1 \mathrm{mg}$ hourly, 44 times, starting $1 \mathrm{hr}$ postovulation, we identified 19
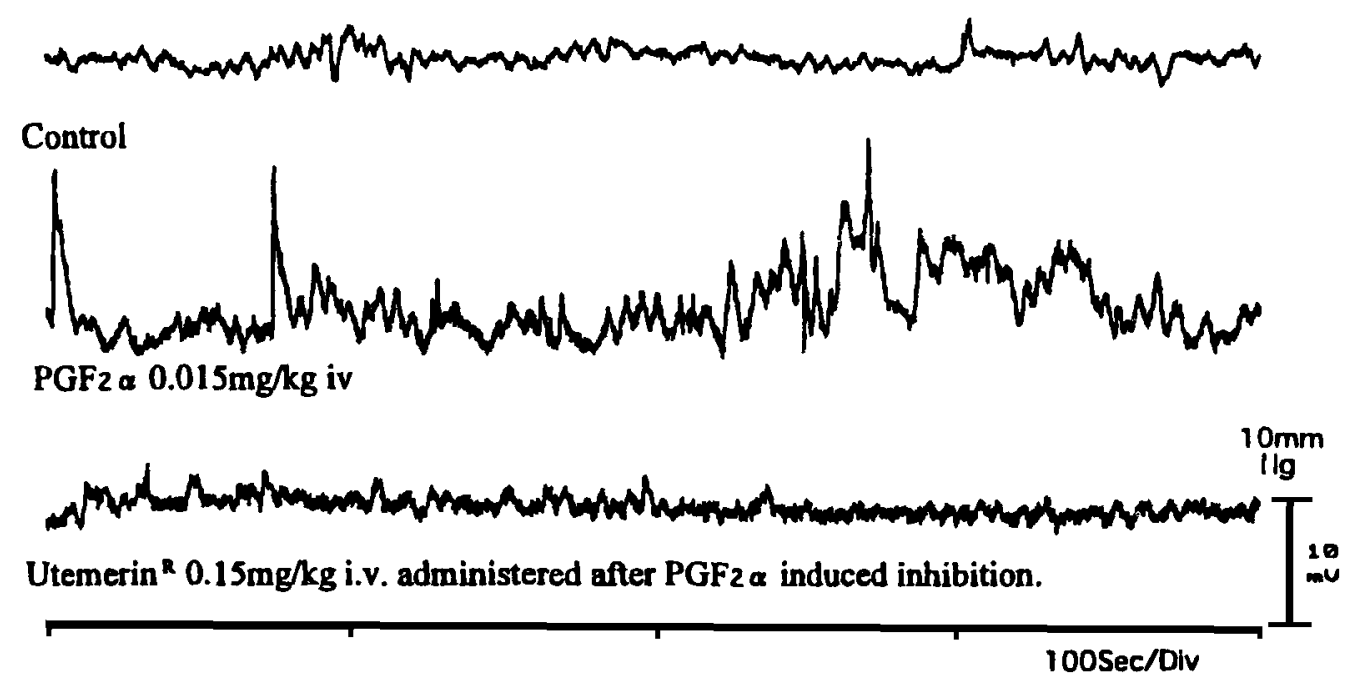

Fig. 1. Tubal intraluminal pressure gradients in response to $\mathrm{PGF}_{2} \alpha$ and Utemerin of the rabbit ampulla. The upper tracing is a control response, showing no apparent reaction other than the normal pattern with no drug effect. The middle tracing shows that both $\mathrm{PGF}_{2} \alpha, 0.015 \mathrm{mg} / \mathrm{kg}$ i.v., and Atonin-O, $0.015 \mathrm{mg} / \mathrm{kg}$ i.v., show similar responses, manifested by increased tubal contractility. The lower tracing shows the effects of Utemerin, in which the incteased contractility is inhibited and the tubal responses return to the pattern seen in the controls. 


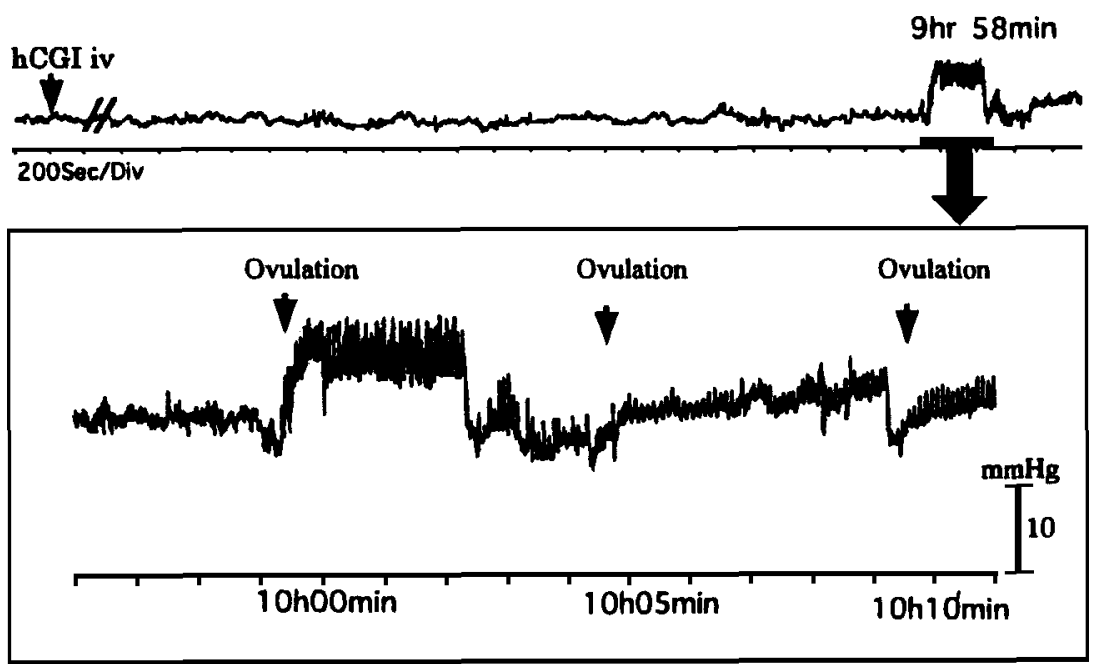

Fig. 2. Tubal intraluminal pressure gradients at ovulation of the rabbit ampulla. The upper panel shows the overall response to a bolus injection of hCG. The lower panel is a magnification of the ampullar response at ovulation. As can be seen, a drop in intraluminal pressure is seen before ovulation, which is signified by an increase in pressure.

ovulation sites on the ovaries. In the ampullae we detected 4 ova $(21 \%)$; and in the isthmic portion of the tube, 11 ova $(57.9 \%)$. (b) In another group $(N=5)$, we performed the same number of Utemerin injections (44) starting $6 \mathrm{hr}$ postovulation. In this group we detected 17 ovulation sites and 12 ova in the midportion of the isthmic tube (70.6\%). However, in this group, no ova were detected in the ampullae. (c) In the third group, with the first injection $12 \mathrm{hr}$ postovulation (44 times) $(N=5)$, we identified 10 ovulations,

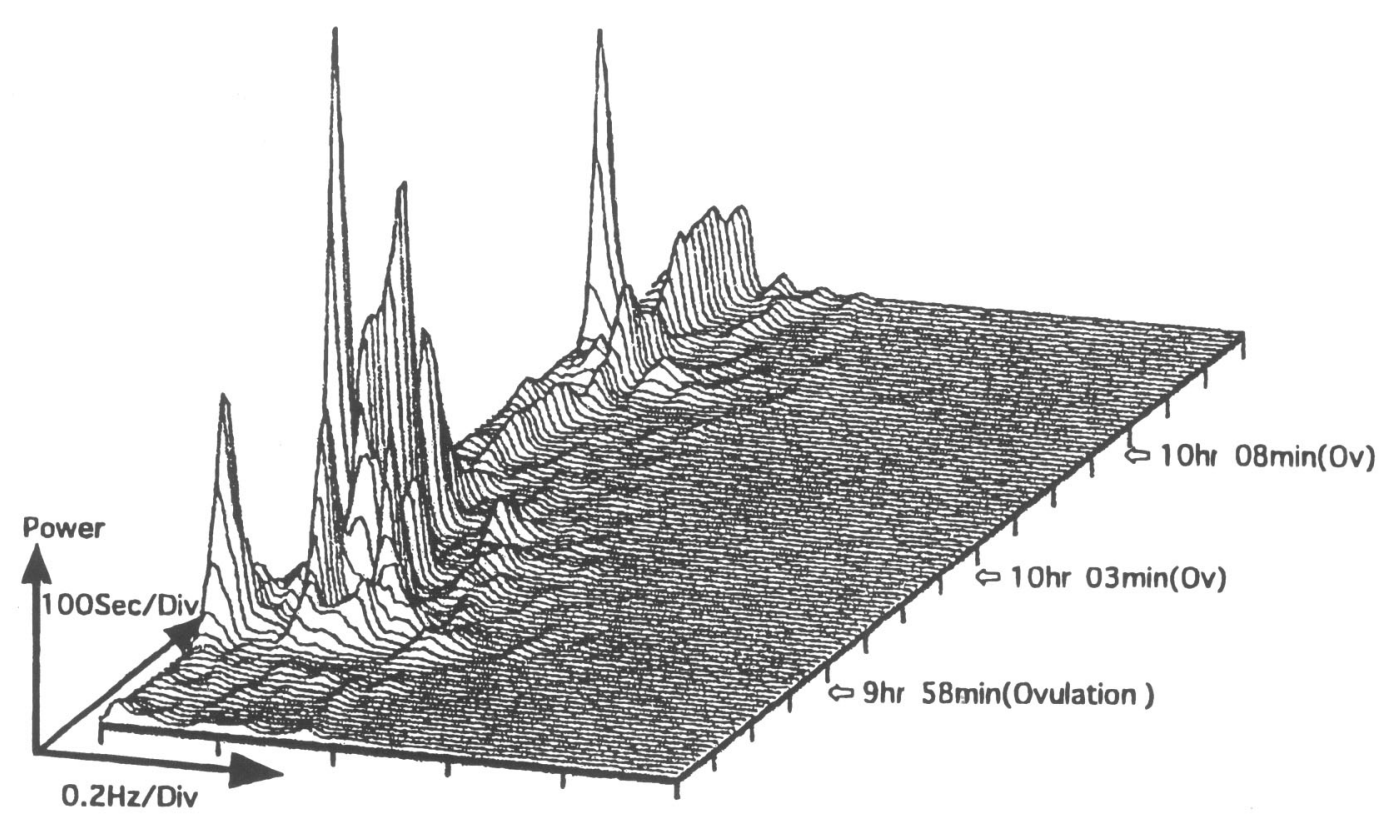

Fig. 3. Power spectrum of tubal intraluminal pressure gradients of the rabbit ampulla. The power spectrum analysis following a bolus injection of hCG, $50 \mathrm{IU} / \mathrm{kg}$ i.v., shows that rabbits ovulate at roughly $10 \mathrm{hr}$ subsequent to the hCG administration. This power spectrum represents the patterns observed during multiple ovulations, the first occurring at $9 \mathrm{hr} 58 \mathrm{~min}$ after the hCG injection. 
with 4 ova in the medial isthmic portion and 4 ova in the uterine cavity, but with no ova in the distal isthmus or ampullae.

Our observations in the three groups receiving Utemerin postovulation revealed a marked inhibition of tubal contractile activity. However, ovum transport was not completely inhibited. This supports evidence that once the ovum has passed into the isthmic portion, ciliary activity becomes more important than changes in intraluminal pressures when considering the mechanisms of transporting the ovum medially toward the uterine cavity. This is in contrast with the ampullar capture of ova expelled from the ovary. The ampullar activity appears to be more dependent on changes in intraluminal pressures caused by contractile activity for the successful capture of ova.

\section{DISCUSSION}

We investigated the physiologic roles of the fallopian tubes and their various parts, including the capture of the ova as they are expelled by the ovaries, together with the accompanying follicular fluid and its various constituents. Once captured by the tubal fimbria, the ova are transported by ciliary activity to the area where they are best fertilized. The tubal environment is also involved in the capacitation of the spermatozoa and ease transport of the sperm to the area where they will fertilize the ova. The tubes also provide an environment conducive to the fertilization and development of the early zygote. The tubal activity is involved in the transport of the zygote medially to aid it in arriving in the uterine cavity, where nidation and further development occur in normal pregnancies.

These various activities occur at definite areas of the tube which can be anatomically designated as the fimbrial tubal structures being involved in the capture of the expelled ova and follicular fluid. The ampullar structures merge with the isthmic portion or the AIJ. It is believed that the ampullar portion distal to the AIJ is where fertilization best occurs, distal to the isthmic portion of the tube is the IUJ. The various portions of the tube appear to have specific and separate functions. It has been demonstrated that rabbits ovulate roughly $10 \mathrm{hr}$ following hCG stimulation (3) and ovulate bilaterally, with up to 10 ova being expelled from each ovary. As this is not a simultaneous event, it requires a given time interval (4). This experiment revealed that the ampullary portion of the tube in rabbits undergoes an increase in tubal activity accompanied by a depression of pressure which syn- chronizes with the event of ovulation. Although it was not demonstrated by this experiment, the material most likely involved in inducing this enhanced tubal activity appears to be $\mathrm{PGF}_{2} \alpha$.

These events, including ovulation, fimbrial capture of the ovum, and increased ampullary activity, all suggest the importance of a series of mechanisms participating in the transport of the ovum to the site of fertilization. We found enhanced tubal contractile activity in the tube near ovulation, as evidenced by changes in intraluminal pressures, and showed that inhibiting this contractile activity effectively inhibits ovum capture.

A rapid increase in $\mathrm{PGF}_{2} \alpha$ in the follicular fluid prior to ovulation has been reported in rats (5) and rabbits (6). In rabbits, it has been reported that follicular preovulatory $\mathrm{PGF}_{2} \alpha$ levels 60 times baseline concentrations can be attained following hCG administration (7). Expelling the ovum together with follicular fluids is accomplished by the contractions of smooth muscle fibers in the follicular wall (8). Rabbit granulosa cells have been reported to synthesize and secrete $\mathrm{PGF}_{2} \alpha$ (9). It may be assumed that this increase in $\mathrm{PGF}_{2} \alpha$ prior to ovulation in the follicular fluid is a requisite to induce contractions of the follicular wall, which then rupture, expelling the ovum and accompanying follicular fluid containing high levels of $\mathrm{PGF}_{2} \alpha$ into the tubal ampulla (10). It is believed that these elevated levels of $\mathrm{PGF}_{2} \alpha$ in the follicular fluid are necessary to enhance ovum capture by the tubal fimbria. Indomethacin, which is known as an inhibitor of PG synthesis, inhibits ovulation (11). The ampullary contractions observed following ovulation were likely to have been caused by the influx of high concentrations of $\mathrm{PGF}_{2} \alpha$, expelled together with the follicular fluid, and inducing smooth muscle contractions of the tubal ampulla.

Once captured by the fimbria, the ovum is said to be transported within a few minutes to the medial ampulla, the region of the AIJ, where it remains for $20-30 \mathrm{hr}$, waiting to be fertilized by sperm cells traveling distally in the tube (12). In rabbits, isthmic contractility following hCG administration reveals an increase in contractile activity which attains maximal levels at $12-36 \mathrm{hr}$ postadministration. This time period corresponds closely to the interval during which the ovum is retained in the ampulla near the AIJ (13). The AIJ is said to delay the transport of the ovum medially and, in effect, acts as a controlling mechanism for the transport of the fertilized ovum toward the uterine lumen. 
Tubal contractility is under the control of the sympathetic nervous system $(14,15)$. The distribution of sympathetic nerve elements is in the inner layer of the annular smooth muscle tissue and is found in increased abundance at the AIJ and UIJ portions of the tubal isthmus $(16,17)$. The outer linear layer and inner annular layer of the tube's smooth muscles contain both $\alpha$ and $\beta$ receptors, the sensitivity of which is affected cyclically by the influence of endocrine substances. When the $\alpha$ receptors are stimulated, there is an increase in contractility, and when the $\beta$ receptors are stimulated, there is an inhibition of contractility. These receptors are highly responsive to sex steroids (18) and prostaglandins and are intimately involved in controlling the rhythmic tubal contractions and relaxations necessary for ovum transport (19-22). In rabbits, the elevated estrogens at ovulation stimulate the $\alpha$ receptors, increasing tubal contractility, and are involved in retaining the ovum in the ampulla near the AIJ. After ovulation, the elevation in progesterone stimulates the $\beta$ receptors, causing relaxation of the AIJ, allowing transport of the ovum into the isthmic portion of the tube $(23,24)$.

Eddy (25) reports that in rabbits, estrogen administration postovulation results in the retention of the ovum near the AIJ. This suggests that estrogen stimulates the $\alpha$ receptors, resulting in increased contractility of the AIJ, which then acts as a limiting sphincter and thus inhibits medial transport of the ova into the isthmic portion of the tube. This was further substantiated by the excision of the AIJ, followed by estrogen, which effectively inhibited medial transport of the ovum in the tubal isthmus. Thus, it is clear that progesterone, which stimulates the $\beta$ receptors, effecting a smooth muscle relaxation in the tubes, is an indispensable factor in allowing the ovum to be transported from the ampulla into the isthmic portion of the tube.

The tubal ampulla distal to the AIJ has been observed to be the optimal site for fertilization. The ova captured by the fimbrial portion are rapidly transported to a location near the AIJ. This process is said to occur in just a few minutes $(26,27)$. This rapid transport of the ova within the ampullary portion is dependent on ciliary activity and tubal smooth muscle contractions. Halbert et al. (28) have reported that, in the rabbit, the ova are transported in the ampulla at a rate of $0.1 \mathrm{~mm} / \mathrm{min}$ and that isoprotenol, a $\beta$ stimulant smooth muscle relaxant, has no effect on slowing this rate, emphasizing the importance of ciliary activity in the transport of ova in the ampullary portion of the tube. These ampullary contractions are probably intimately involved in the transport of the ova toward the uterine cavity, during which time the ova may be fertilitized. Thus, we feel that the high concentrations of $\mathrm{PGF}_{2} \alpha$ observed in the follicular fluid are highly important in inducing transport of the ova from the follicle to the ampulla, then through the tube, until they finally arrive at the uterine cavity for nidation and further development.

\section{CONCLUSIONS}

In conclusion, our data based on telemetry received signals revealed that rabbits injected with $\mathrm{hCG}$ respond by ovulating at $9.5 \pm 1.6 \mathrm{hr}$ postinjection, as evidenced by a sharp drop in tubal pressure, followed by a recovery to twice the control levels, with a disparity in intratubal pressures between contractions and relaxations roughly three times those seen under control conditions.

In intact rabbit fallopian tubes, $\mathrm{PGF}_{2} \alpha$ and Atonin$O$ both cause an increase in tubal contractile activity which is effectively inhibited by Utemerin. Utemerin effectively inhibits tubal contractile activity as demonstrated by a failure to capture ova expelled from the ovaries. However, this inhibitory activity of Utemerin can be reversed by the subsequent administration of $\mathrm{PGF}_{2} \alpha$, which restimulates the tubal tissues to commence contractile activity, and thus allow the fimbrial portions of the tubal ampullae actively to capture ova. Once the ova are captured, Utemerin has an inhibitory influence on ovum transport but is unable to halt this process completely, indicating that once the ovum is captured, ciliary activity is more important than tubal contractility in transporting the ova toward the uterine cavity.

\section{ACKNOWLEDGMENTS}

We wish to thank the Department of Veterinary Physiology, College of Bioresource Science, Nihon, University, especially Dr. K. Kanayama, Tsuyoshi Endo, and their co-workers, for their cooperation.

\section{REFERENCES}

1. Frederiks CM, Azzam MEA, Hafes ESE: The motility in vitro of the rabbit utero-ovarian ligament. J Reprod Fertil 1977;49:387-389

2. Halbert SH, Conral JT: In vitro contractile activity of the mesotubarium superius from the rabbit oviduct in various endocrine status. Fertil Steril 1975;26:248-256 
3. Overstreet JW: Sperm numbers and fertilization in the rabbit J Reprod Fertil 1970;21:279-288

4. Harper MJK: Ovulation in the rabbit: The time of follicular rupture, expulsion of the eggs, in relation to injection of luteinizing hormone. J Endocrinol 1963;26:307-316

5. Armstrong DT, Grinwich DL: Blockade of spontaneous and LH-induced ovulation in rats by indomethacin, an inhibitor of prostaglandin biosynthesis. Prostaglandins 1972;1:21-28

6. Armstrong DT, Grinwich DL, Moon YS, Zanecnik J: Inhibition of ovulation in rabbits by intrafollicular injection of indomethacin and $\mathrm{PGF}_{2} \alpha$ anti-serum. Life Sci 1974;14:129-140

7. LeMaire WJ, Yang NS, Behrmam HR, Marsh JM: Preovulatory changes in the concentration of prostaglandins in rabbit Graafian follicles. Prostaglandins 1973;3:367-376

8. Okamura H, Okazaki T, Nakajima A: Effects of neurotransmitters and prostaglandins on human ovarian contractility. Obstet Gynecol 1974;44:720-726

9. Challis JRG, Erickson GF, Ryan KJ: Prostaglandin F production in vitro by granulosa cells from rabbit preovulatory follicles. Prostaglandins 1974;7:183-193

10. LeMaire WJ, Marsh JM: Interrelationship between prostaglandins, cyclic AMP and steroids in ovulation. $J$ Reprod Fertil Suppl 1975;22:53-74

11. Ainsworth L, Tsang BK, Downey BR, Baker RD, Marcus TJ, Amstrong DT: Effects of indomethacin on ovulation and luteal function in gilts. Biol Reprod 1979;21:401-412

12. Greenwald GS: A study of the transport of ova through the rabbit oviduct. Fertil Steril 1961;12:80-95

13. Spilman CH, Shaikh AA, Harper MJK: Oviductal motility amplitude and ovarian steroid secretion during egg transport in the rabbit. Biol Reprod 1978;18:409-417

14. Bodkhe RR, Harper MJK: Changes in the amount of adrenergic neurotransmitter in the genital tract of untreated rabbits and rabbits given reserpine or iproniazid during the time of egg transport. Biol Reprod 1972;6:288-297

15. Hodgson BJ, Eddy CA: The autonomic nervous system and its relationship to tubal ovum transport-A reappraisal. Gynecol Invest 1975;6:162-185

16. Brundin J: Distribution and function of adrenergic nerves in the rabibit fallopian tube. Acuta Physiol Scand 1965;66 (Suppl 259):1-57
17. Paton DM, Widdicombe JH, Rheaume DE, Johns A: The role of the adrenergic nervous innovation of the oviduct in the regulation of mammalian ovum transport. Pharmacol Rev 1977;29:67-102

18. Pauerstein CJ, Hodgson BJ, Fremming BD, Martin JE: Effects of sympathetic denervation of the rabbit oviduct on normal ovum transport and on transport modified by estrogen and prosterone. Gynecol Invest 1974;5:121-132

19. Hodgson BJ: Effects of indomethacin, ICI 46:474 administrated during ovum transport on fertility in rabbits. Biol Reprod 1976;14:451-457

20. Horton EW, Main IHM, Thompson CJ: Effects of prostaglandins on the oviduct, studied in rabbits and ewes. J Physiol 1965;180:514-538

21. Rajkumar K, Garg SK, Sharma PI: Relationship between concentration of prostaglandins $E$ and $F$ in the regulation of ovum transport in rabbits. Prostaglandins Med 1979;2:445-454

22. Riehl RM, Harper MJK: Changes in prostaglandin binding capacity of single oviductal smooth muscle cells after ovulation in the rabbit. Endocrinology 1981;109:1011-1016

23. Caschetto S, Lindlom B, Wiqvist N, Wilhelmsson L: Prostaglandins and the contractile function of the human oviductal ampulla. Gynecol Obstet Invest 1979;10:212-220

24. Helm G, Owman C, Sjoberg NO, Walles B: Motor activity of the human fallopian tube in vitro in relation to plasma concentration of oestradiol and progesterone, and the influence of noradrenaline. J Reprod Excerpta Fertil 1982; 64:233-242

25. Eddy CA, Balmaceda JP, Pauerstein CJ: Effect of resection of the ampullary isthmic junction on estrogen induced tubal locking ova in the rabbit. Biol Reprod 1978;18:105-109

26. Boling JF, Blandau RJ: Egg transport through the ampullae of the oviducts of rabbits under various experimental conditions. Biol Reprod 1971;4:174-184

27. Harper MJK: Transport of eggs in cumulus through the ampulla of the rabbit oviduct in relation to day of pseudopregnancy Endocrinology 1965;77:114-123

28. Halbert SA, Tam PY, Blandau RJ: Egg transport in the rabbit oviduct: The role of cilia and muscle. Science 1976;191:10521053 